\title{
Assimilação na Libras
}

\author{
Carolina Silva Resende da Nóbrega ${ }^{1}$
}

\section{Resumo}

A assimilação é um dos processos fonológicos mais comuns da Libras. Neste trabalho, analisam-se e classificam-se as assimilações encontradas em narrativas produzidas por surdos brasileiros. Foram observados três tipos principais de assimilação, todos motivados pelo contexto imediato: a regressiva, a progressiva e a simultânea. Conforme previsto por Liddell e Johnson (1989), mencionam processos de assimilação em todos os tipos de parâmetros: configuração de mão, ponto de articulação, movimento e orientação de mão. Além disso, para diferenciar as assimilações que afetam componentes distintivos da forma do sinal daquelas que afetam componentes não distintivos, foi introduzida a oposição entre assimilação forte e fraca.

Palavras-chave: Libras. Processos fonológicos. Assimilação.

\section{Abstract}

The assimilation is one of the most common phonological processes in Libras. This article, analyzes and classifies the assimilations that are found in narratives produced by deaf Brazilians. Three main types of assimilation

${ }^{1}$ Doutoranda e docente da Universidade Federal da Paraíba - UFPB, João Pessoa Paraíba. E-mail: profcarolinanobrega@gmail.com 
were observed, all motivated by the immediate context: the regressive, the progressive and the simultaneous. Liddell and Johnson (1989) mention assimilation processes in all types of parameters: handshape, location, movement and orientation. After this, to differentiate the assimilations that affect the distinctive components from the signal shape of those that affect non-distinctive components, the opposition was introduced between strong and weak assimilation.

Keywords: Libras. Phonological processes. Assimilation

\section{Introdução}

Para a descrição da assimilação na Língua Brasileira de Sinais Libras, adotamos o conceito consagrado para a assimilação em línguas orais por Gabas Júnior (2008) e já utilizado por Liddell e Johnson (1989) na análise da Língua de Sinais Americana - ASL. Os estudos sobre a assimilação em línguas orais remontam à Antiguidade e estão entre os fenômenos mais conhecidos da Linguística. Os estudos sobre o fenômeno nas línguas de sinais, entretanto, são ainda escassos e, como os demais estudos das línguas de sinais, são muito recentes, visto que a pesquisa científica dessas línguas começou apenas na década de 70 do século XX, com William Stokoe (1960), nos Estados Unidos. No Brasil, esses estudos são ainda mais recentes, destacando-se, entre outros, o trabalho pioneiro de Ferreira Brito (1995).

Apesar de não dispormos ainda de uma descrição consolidada da fonologia da Libras, levamos adiante o estudo da assimilação, utilizando como base de análise desses processos os parâmetros visuais que constituem a forma dos sinais e que passaremos a denominar "fonemas" e suas classes, estabelecidos inicialmente por Stokoe (1960) e revisitados por diversos autores para a ASL, que também são adotados nos estudos 
da Libras. A metodologia consiste em analisar e identificar os sinais através de vídeos de colaboradores surdos narrando suas histórias escolhidas e categorizadas por mim. Além da identificação foi possível reconhecer e classificar vários tipos de processos de assimilação, alguns já conhecidos nas línguas orais e também relatados em estudos de línguas de sinais, como as assimilações: regressiva e progressiva. Além desses, identificamos também outro tipo, a assimilação que denominamos simultanea, que não ocorre em línguas orais, pois envolve o uso simultâneo de dois articuladores da mesma natureza - as duas mãos - sendo, portanto, específica de línguas de sinais. Por outro lado, nos estudos de assimilação da ASL e da Libras são relatados apenas processos que envolvem configuração de mãos de Liddell e Johnson (1989). Já neste trabalho de pesquisa, é possível identificar processos de assimilação em todos os parâmetros fonológicos utilizados na Libras: configuração de mão (doravante, $\mathrm{CM}$ ), ponto de articulação, orientação e movimento.

\section{Fundamentação Teórica}

Nos estudos sobre assimilação na Libras é preciso analisar e identificar as regras que explicavam as mudanças fonéticas provocadas por sons "mais fortes" sobre sons "mais fracos", ou seja, buscar referências linguísticas da assimilação da língua oral e transformá-la para a Libras. Há registro teórico que, segundo Gabas Júnior (2008, p. 83), por exemplo, existem basicamente três tipos de assimilação nas línguas orais: progressiva, regressiva e de enfraquecimento. $\mathrm{O}$ autor analisa, no quadro da linguística histórica, as mudanças da língua latina para o português, e do inglês antigo para inglês médio, para comparar os tipos de assimilação, que define como "os processos pelos quais um som condiciona a ocorrência de outro som, tanto no ponto ou modo de articulação".

No caso do desenvolvimento do latim para o português, o autor exemplifica a assimilação regressiva envolvendo vogais, na qual uma vogal 
central passou a vogal posterior, por assimilação à vogal posterior que a seguia:

Quadro 1 - Assimilação regressiva
\begin{tabular}{|c|c|}
\hline Latim & Português \\
\hline aut & ou \\
\hline aurum & ouro \\
\hline taurum & touro \\
\hline
\end{tabular}

Fonte: (GABAS JÚNIOR, 2008, p. 83)

Para a assimilação progressiva, que envolve um som que se assimila a outro que o precede, o processo é exemplificado com a mudança da consoante nasal / $\mathrm{n} /$ para a lateral / $/$ no contexto, quando precedido por /1/, do inglês antigo para o inglês médio, conforme mostra o quadro 2 :

Quadro 2 - Assimilação progressiva

\begin{tabular}{|c|c|c|}
\hline Inglês antigo & Inglês médio & \\
\hline eln & elle & "unidade de medida" \\
\hline myln & mille & "moinho" \\
\hline
\end{tabular}

Fonte: (GABAS JÚNIOR , 2008, p. 84)

Neste momento retratamos as ocorrências de assimilação relatadas por Liddell e Johnson (1989, p. s/n), que está a do sinal ME 'mim', que tipicamente assimila a configuração de mão do constituinte contíguo na oração. Assim, embora a forma subjacente (isolada) de ME seja realizada como dedo indicador apontando para o peito do falante, com a CM em 
2, como se pode ver no primeiro desenho da figura (1), CM,ME na sequência ME GULP (port. me engasgar), apresenta outra $\mathrm{CM}^{\mathrm{M}}$, a mesma de GULP (port. engasgar), ( $\mathrm{CM}_{0}$ ), quando vem junto a esse sinal, como no terceiro desenho da mesma figura.

Figura 1 - Assimilação de Configuração de mão

\section{MOTHER 3ASTARE-ATI. ME GULP}

"Minha mãe estava olhando para mim e eu estava me engasgando" 3
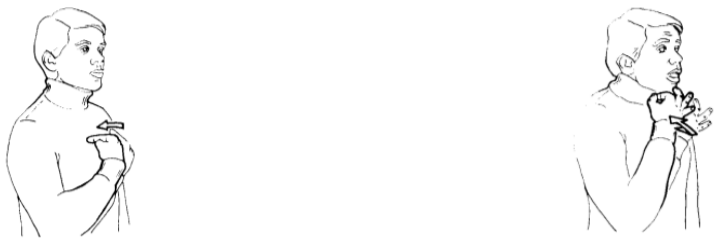

$\mathrm{ME}(\mathrm{EU})$ forma isolada

GULP (ENGASGAR) forma isolada

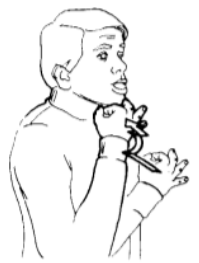

ME GULP (EU ENGASGAR) forma com assimilação

Fonte: (LIDDELL e JOHNSON, 1989, p. s/n [tradução da autora])

$\mathrm{Na}$ Libras, há registros de três referências à processos de assimilação: a assimilação de CM nos trabalhos de Leite (2008) e de McCleary e Leite (2012), e a assimilação na mudança histórica de sinais compostos que resultaram na formação de sinais simples em Diniz (2011).

2 Agradecemos a LSB Vídeo (Língua de Sinais Brasileira Ltda.) pela autorização da reprodução das imagens das configurações de mão.

3 Tradução do inglês: Mother was staring at me and I was nervous about what was to come. 
Segundo Leite (2008, p. 218), há “assimilação da configuração de mão do sinal subsequente pelo sinal inicial, em sua fase expressiva ${ }^{4}$ ou até mesmo em sua fase de preparação". No exemplo dado pelo autor, reproduzido a seguir na figura 2, ocorre uma assimilação regressiva parcial da configuração de mão do primeiro sinal, VOCÊ, que se realiza na sua fase expressiva com a configuração do segundo sinal da sequência, OBRIGAR.

Figura 2 - Assimilação da configuração de mão de sinais em posição frasal inicial

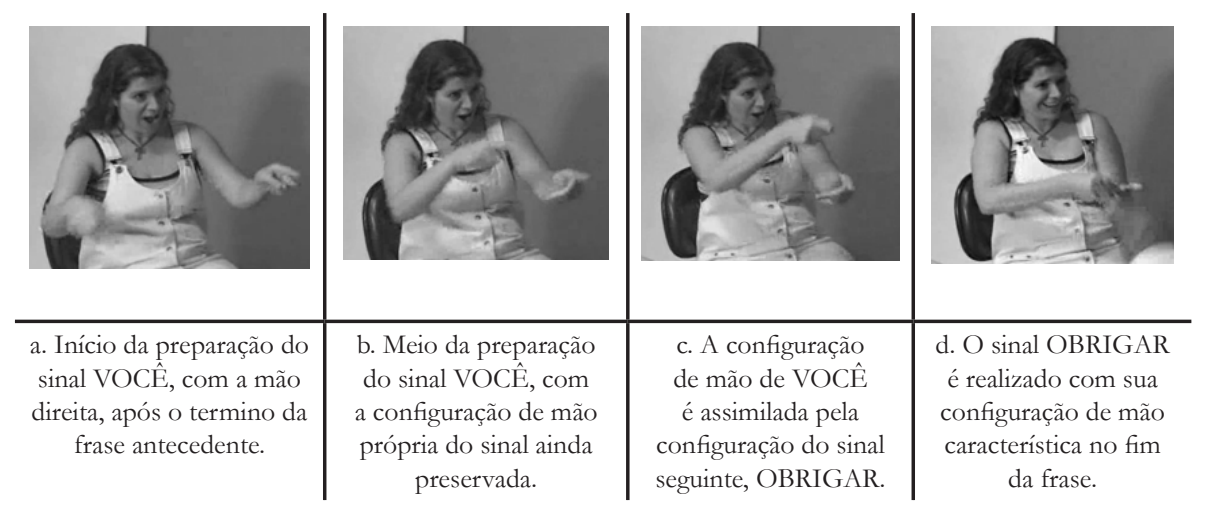

Fonte: LEITE (2008, p. 218)

\section{O autor explica o processo:}

Até certo ponto da fase de preparação do sinal VOCẾ (imagens a e b), a falante ainda preserva a configuração de mão em "G1", própria do sinal VOCÊ. Quando o sinal atinge a fase expressiva (imagem c), contudo, a configuração de mão em " $\mathrm{A}$ ", própria do sinal subsequente na frase, OBRIGAR (imagem d), é assimilada. (LEITE, 2008, p.218).

McCleary e Leite (2012), por sua vez, atribuem a ocorrência de assimilação ao aumento da velocidade da fala e para isso apresentam exemplos de assimilação de CM em sinais contíguos.

${ }^{4}$ Em cada sinal, o autor identifica três fases: a de preparação, a expressiva e a de retração. (LEITE, 2008, p. 147). 
Já Diniz (2011, p. 109), numa perspectiva de mudança histórica, entende que a assimilação "é o tipo de tendência, no qual os sinais compostos se transformam em unitários". Para exemplificar essa tendência, a autora compara exemplos de três dicionários: o dicionário denominado Iconographia dos Signaes dos Surdos-Mudos, de 1875; o dicionário Linguagem das Mãos, de 1969; e o Dicionário Digital da Libras do INES, de 2006, que constituem registros de diferentes fases da Libras. O uso do termo "assimilação" por Diniz, entretanto, não corresponde ao conceito geral de assimilação nas línguas orais e nos estudos das línguas de sinais reportados até aqui. Mesmo assim, nesse estudo, as assimilações observadas incidiram sobre as CMs.

\section{Metodologia}

A metodologia deste artigo envolveu, além do levantamento bibliográfico sobre identificar os sinais da assimilação na Libras e o referencial teórico que adotamos, um levantamento de dados para a análise, no período de maio a outubro de 2012. Foram identificados conceitos em que os autores selecionados para abordagem destes referenciais foram Liddell e Johnson (1989). Os dados foram coletados por meio de gravações individuais de informantes surdos, falantes de Libras, moradores de Brasilia e de Minas Gerais $^{5}$, que foram solicitados a narrar pequenas histórias de sua escolha e a relatar o que haviam visto no filme The pear story, disponibilizado na internet. O corpus desta pesquisa é constituído por dez gravações, identificadas pelas siglas dos títulos das histórias: Kauá diferente (KD), Vestibular (V), Piada açúcar grátis (PAG), Poesia sonho (PS), Pixar: Geri’sGame (PX), Cidade vagalume (CV) e História da pêra (P). Os sinais identificados foram agrupados de acordo com o referencial teórico pertinente. Este agrupamento foi realizado através de diferentes "tipologias".

5 Aprovação do Comitê de Ética em Pesquisa, Instituto de Ciências Humanas na Universidade de Brasília, número do projeto: 15-06/2012. 


\section{Tipos de assimilação da Libras}

Os dados apresentam numerosos processos que diferenciam os sinais na conversação corrente dos sinais produzidos isoladamente. Entre eles, encontram-se os processos de assimilação.

Um exemplo desse tipo de processo ocorre na frase MILHO TAMBÉM ÁRVORE 'milho também é árvore', ilustrado em (1).

1)

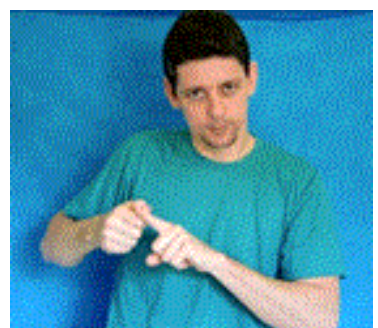

MILHO

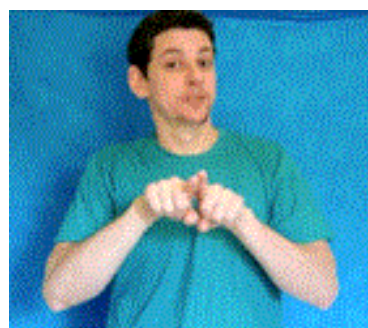

TAMBÉM

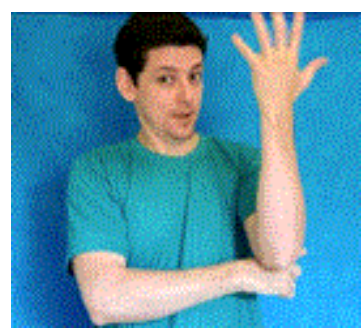

ÁRVORE

Milho também é árvore. (CV: 01:12 - 01:14) (foto da autora)

Convém salientar que nesse exemplo, em que os sinais envolvidos são todos realizados com duas mãos, o processo de assimilação afeta a realização do sinal resultante em suas propriedades configuracionais básicas. Neste caso afeta a CM da mão passiva de ÁRVORE, que, na sua forma isolada seria mas que, depois da assimilação da CM de TAMBÉM, se apresenta com a CM Denominamos esse tipo de processo assimilação forte.

Para as LS, consideramos essencial, inicialmente, fazer uma distinção que não é necessária nas línguas orais: a assimilação forte e a fraca. A assimilação forte é aquela que, ao trazer para o sinal alvo uma característica do sinal disparador, modifica algum parâmetro pré-existente do sinal alvo (na sua forma isolada), enquanto a assimilação fraca traz para o sinal alvo uma característica do sinal disparador, acrescentando marginalmente uma característica que não afeta os parâmetros pré-existentes desse sinal. Se 
compararmos com a assimilação das línguas orais, teremos que dizer que, nessas, toda assimilação é forte, pois resulta na modificação de algum segmento pré-existente na forma isolada ou subjacente.

A assimilação fraca ocorre apenas em sinais alvos realizados com uma só mão, pois ela afeta apenas a mão não utilizada na expressão do sinal. Nesses casos, o parâmetro antecipado ou retardado que aparece na realização do sinal alvo, provém sempre de sinais disparadores que utilizam as duas mãos, sejam aqueles que apresentam simetria das duas mãos como aqueles nos quais a mão passiva faz parte do sinal de maneira assimétrica.

São exemplos com assimilação fraca IDEIA, em FOME IDEIA 'estou com fome, é uma boa ideia!' (exemplo (2), e VESTIBULAR, em (4), PROVA VESTIBULAR 'a prova do vestibular', abaixo:

2)

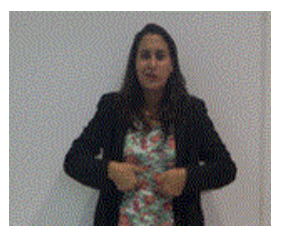

FOME

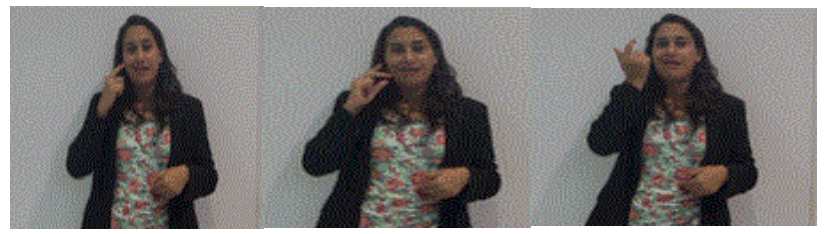

IDEIA

Estou com fome, é uma boa ideia! (PAG: 00:20 - 00:21) (foto da autora)

3)

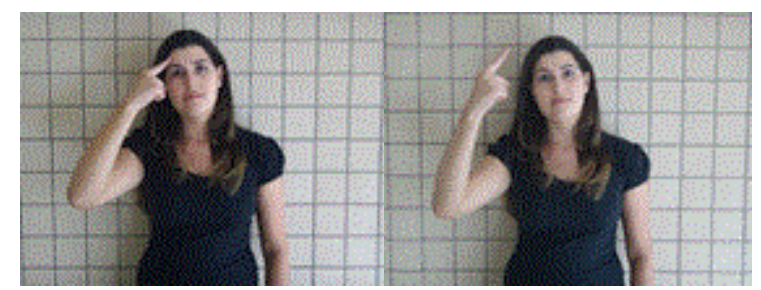

IDEIA - forma isolada (foto da autora) 
No primeiro exemplo, o sinal FOME, realizado com as duas mãos em CM Ė , na altura do estômago, simetricamente, é seguido por IDEIA, que, em sua forma isolada, é realizado apenas com uma mão (exemplo 3). $\mathrm{Na}$ frase FOME IDEIA, exemplificada em (2), entretanto, a mão passiva de FOME é mantida em IDEIA, num processo de assimilação fraca.

O mesmo ocorre com a mão passiva de PROVA no exemplo (4), antecipada por assimilação fraca em VESTIBULAR.

4)

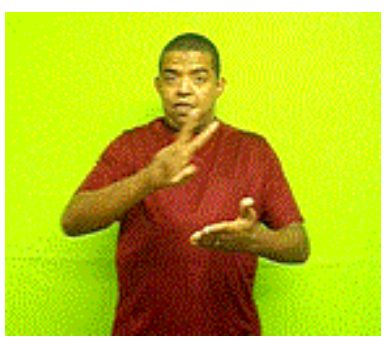

VESTIBULAR

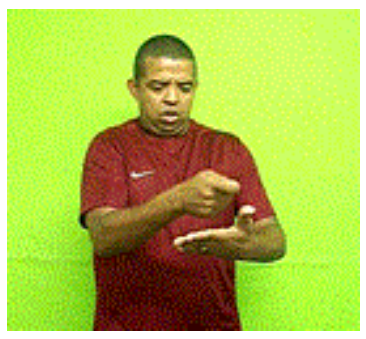

PROVA

A prova do vestibular. (V:00:17 - 00:18) (foto da autora)

Note-se que esse tipo de processo é relatado como processos distintos da assimilação por autores que descreveram a ASL. Valli et al. (2011, p. 48) interpretam-no como epêntese e Liddell e Johnson (1989) como "perseveração e antecipação". Há divergência dessas interpretações, pois a epêntese em geral não copia traços dos segmentos vizinhos e, por outro lado, a interpretação de Liddell e Johnson corresponde às características definitórias da assimilação, de modo que não há necessidade de criar um novo tipo de processo. Nos exemplos (2) e (4) da Libras, acima, para compreender, portanto, como assimilação a presença da mão passiva (do sinal disparador) na realização de um sinal que utiliza na sua forma isolada apenas a mão dominante aponta a permanência do uso do sinal assimilando, posteriormente e juntamente, ao sinal alterado, da mão dominante. 
Neste caso, é considerado como fonemas, a análise de diferentes manifestações dos parâmetros configuração de mão, ponto de articulação, movimento e orientação. A pesquisa teve como foco a análise das modificações de forma que os sinais sofrem devido ao contexto imediato, ou seja, devido ao que vem imediatamente antes, depois ou junto com o sinal, no fluxo da conversação.

Além dessa distinção, entre assimilação forte e fraca, outras distinções se fazem necessárias para classificar os tipos de assimilação encontrados nos nossos dados. Prosseguindo, entre outros, os critérios definidos para classificar os processos de assimilação em línguas orais, ou seja, (1) qual a posição relativa entre o disparador e o alvo, que denominaremos 'motivação da assimilação' e (2) em que proporção a assimilação atinge o segmento alvo: total ou parcialmente.

\section{A Assimilação motivada por fonemas contíguos}

Distinguem-se dois tipos principais de assimilação na Libras: os processos motivados por fonemas contíguos, e os motivados por fonemas realizados simultaneamente. Esses últimos são exclusivos das línguas de sinais e não ocorrem nas línguas orais devido à linearidade dessas línguas, que não permite a ocorrência de segmentos simultâneos.

Na primeira categoria, são agrupados os processos de assimilação motivados por fonemas contíguos, que podem ocorrer precedendo ou seguindo o sinal com assimilação.

\section{Assimilação progressiva}

É aquela em que uma característica do sinal anterior se mantém no sinal seguinte. Um exemplo desse tipo de assimilação aparece em (5) BANHAR-TINTA ENTENDER traduzido como "Ele tomou um banho de tinta e entendeu". 
5)

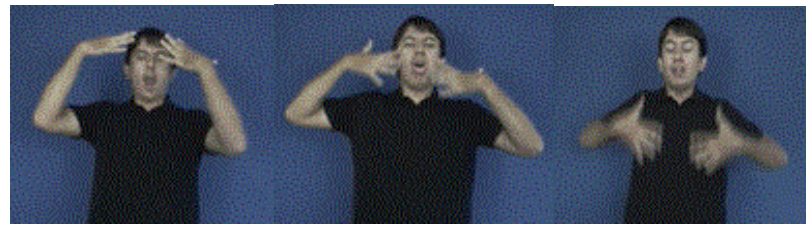

BANHAR-TINTA

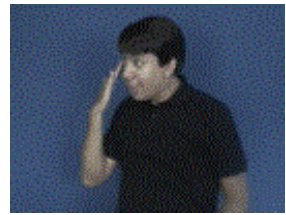

ENTENDER

Ele tomou um banho de tinta e entendeu. (KD: 10:07 - 10:08) (foto da autora)

$\mathrm{Na}$ sequência, temos BANHAR-TINTA e ENTENDER. A configuração de mão do sinal BANHAR-TINTA é a CM a forma isolada de ENTENDER, é a CM Ê, como se pode ver no exemplo (6).

6)

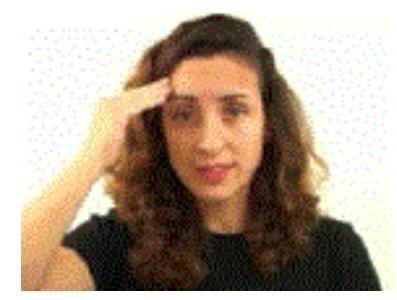

ENTENDER - forma isolada (Fonte: Acesso Brasil)

Mas na sequência em questão, do exemplo (5), o sinal ENTENDER é realizado com a configuração de mão CM do sinal precedente BANHAR-TINTA.

\section{Assimilação regressiva}

Possui a antecipação de uma característica do segundo sinal no sinal que o precede, como se pode ver no exemplo (7) VESTIBULAR PROVA equivalente ao português "A prova do vestibular". 


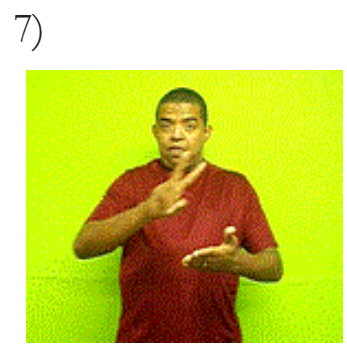

VESTIBULAR

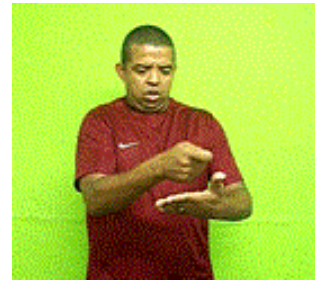

PROVA

A prova do vestibular. (V:00:17 - 00:18) (foto da autora)

No enunciado VESTIBULAR PROVA, que ocorre na narrativa "Vestibular", o sinal VESTIBULAR antecipa, na mão passiva, a configuração de mão é um caso de assimilação regressiva de configuração de mão pelo fato de o sinal VESTIBULAR ser realizado apenas com a mão dominante em outras ocorrências, como se pode ver na forma isolada em (8).

8)

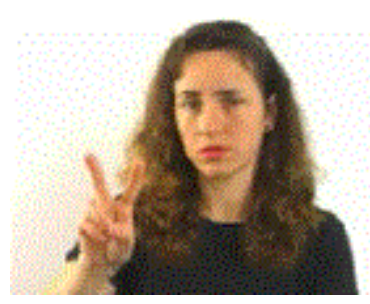

VESTIBULAR -forma isolada (Fonte: Acesso Brasil)

Note-se que o tipo de assimilação do exemplo acima ocorre com a permanência do traço da mão passiva de PROVA num sinal que não utiliza essa mão, o sinal de VESTIBULAR, constituindo, como vimos anteriormente, um exemplo de assimilação fraca. 


\section{Assimilação simultânea}

Nesses dados, esse apareceu em um tipo de processo de assimilação que não ocorre em línguas orais. Esse tipo de assimilação é consequência da possibilidade de articular um sinal com duas mãos.

$\mathrm{Na}$ assimilação simultânea há a modificação da CM da mão passiva por influência da CM da mão ativa. No exemplo (9), PROCURAR 'eu procurei’, a CM da mão passiva se inicia em mas ao longo da realização

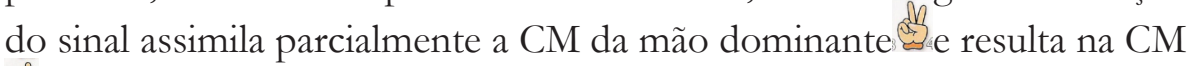
बी.

9)

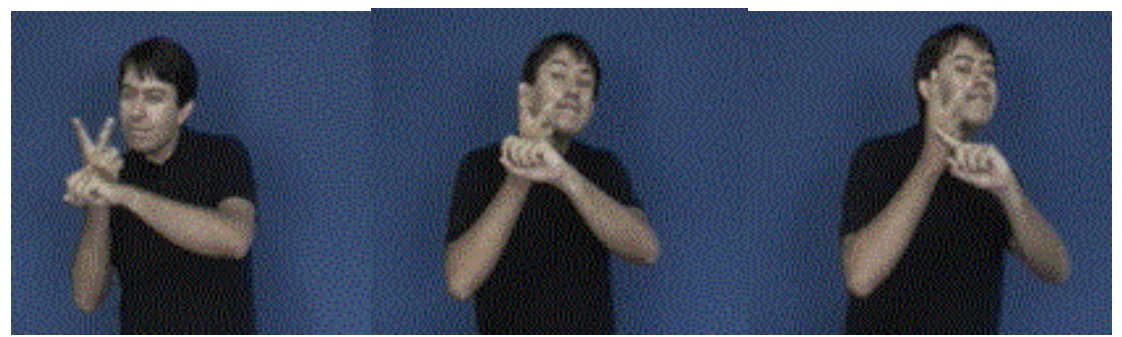

PROCURAR

'Eu procurei' - (KD: 06:48 - 06:49) (foto da autora)

Note-se que na forma isolada de PROCURAR (exemplo 10), a CM da mão passiva não se altera, sendo realizada com a CM durante todo o sinal.

10)

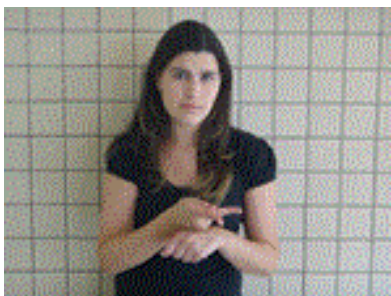

PROCURAR - Forma isolada (foto da autora) 
Por outro lado, convém salientar que o processo de assimilação identificado no exemplo (9) não se deve a influências nem do contexto anterior nem do contexto posterior à realização do sinal, como se pode ver no trecho transcrito no exemplo (11):

11)

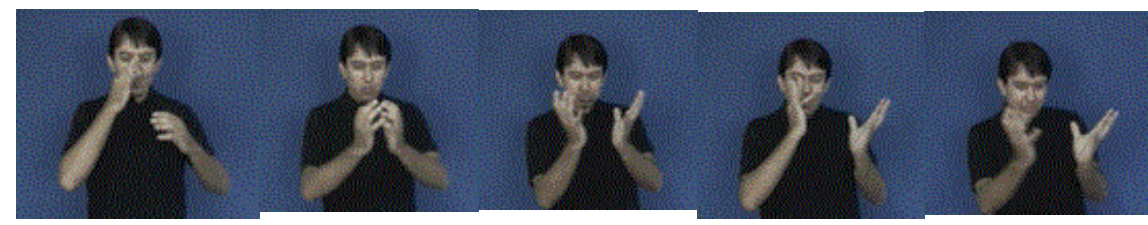

$\begin{array}{lll}\text { FLOR BUQUÊ } & \text { FLOR }\end{array}$

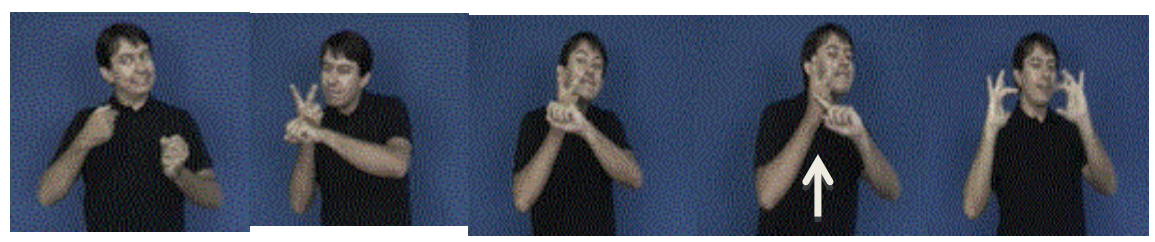

SEGURAR-BUQUÊ EU PROCURAR NAMORADA

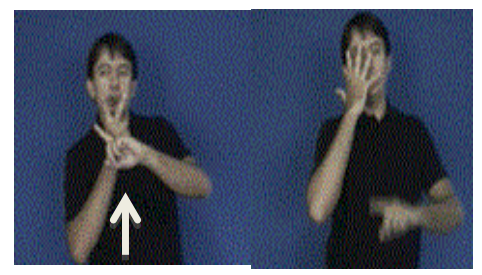

PROCURAR BONITA

Com um buquê de flores eu vou procurar uma namorada bonita. (KD: 06:44 - 06:52) (foto da autora)

Como se pode observar no enunciado em contexto maior, a assimilação da CM não se deve nem às CMs dos sinais precedentes, EU e BUQUÊ, nem à CM do sinal seguinte, NAMORADA, que é realizado com as duas mãos, com outra CM. Embora a CM de EU também seja esse sinal foi realizado com a mão ativa e no sinal PROCURAR essa CM 
é utilizada na parte passiva do sinal. Por outro lado, a mão passiva de PROCURAR, no sinal precedente realiza o sinal SEGURAR-BUQUÊ, simultâneo ao sinal EU.

Um aspecto a salientar em relação à assimilação simultânea devese ao fato de ela não ser provocada por parâmetros de sinais vizinhos e sua presença ou ausência possivelmente se deva, como no caso citado por McCleary e Leite (2012, p. 19-20), a diferentes velocidades na fala.

\section{Assimilação total}

Aquela em que o sinal alvo reproduz completamente uma parâmetro do sinal que provoca a assimilação. Esse tipo de processo ocorre no exemplo (12), no qual a CM de TAMBÉM, se mantém na mão passiva do sinal seguinte ÁRVORE, constituindo, por outro lado, uma assimilação progressiva.

12)
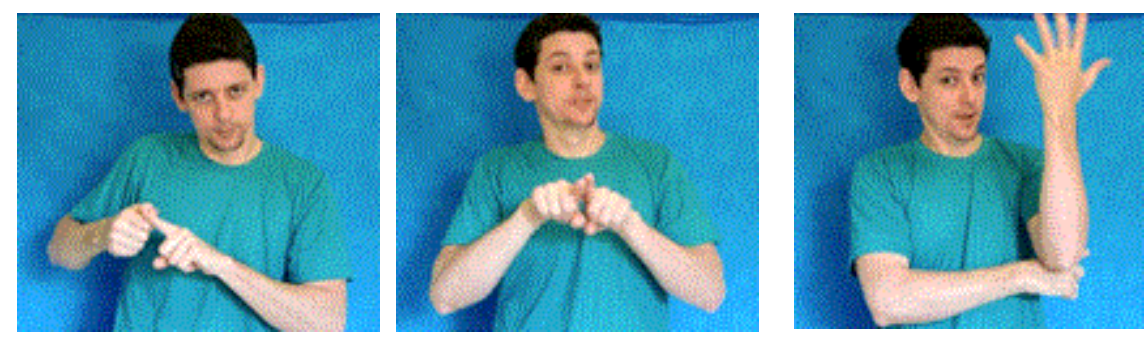

MILHO

TAMBÉM

ÁRVORE

Milho também é árvore. (CV: 01:12 - 01:14) (foto da autora)

\section{Assimilação parcial}

Nesta categoria apenas uma parte da configuração de mão é reproduzida no sinal alvo. O sinal PARECER, por exemplo, que na sua 
forma isolada apresenta a CM e também movimento (como se pode ver no exemplo 14), no enunciado 'Parece mostrar-se (jovem)' (13), além de eliminar o movimento, assimila parcialmente o dedo indicador da $\mathrm{CM}$ do sinal MOSTRAR (exemplo 15), enquanto o polegar fica afastado, na $\mathrm{CM}$ 입.

13)

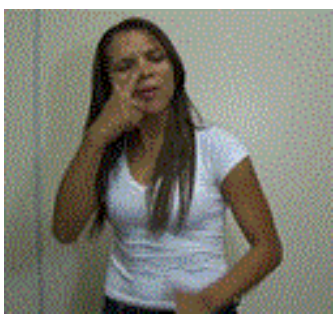

PARECER

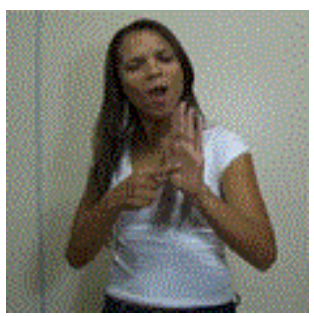

MOSTRAR (CM 14)

Parece mostrar-se (jovem). (PX: 00:51) (foto da autora)

14)

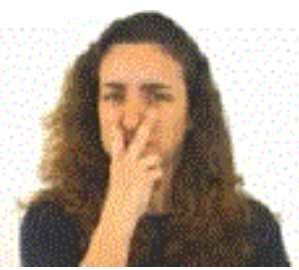

PARECER - forma isolada (Fonte: Acesso Brasil)

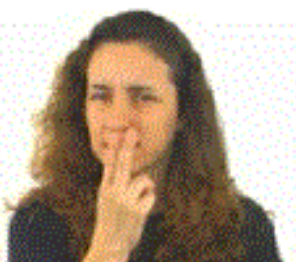

15)

MOSTRAR - forma isolada (Fonte: Acesso Brasil)

Convém notar que o exemplo (13), além de constituir um caso de assimilação parcial, também caracteriza uma assimilação forte e regressiva. 


\section{Assimilação de diferentes parâmetros em LIBRAS}

Os processos de assimilação de todos os parâmetros em nossos dados são encontrados nos parâmetros da Libras, que será subdividido em configuração de mão, ponto de articulação, movimento e orientação de mão.

\section{Assimilação de Configuração de Mão (CM)}

A assimilação de Configuração de Mão (CM) reproduz total ou parcialmente a CM de um sinal vizinho ou simultâneo.

Encontra-se esse tipo de assimilação no exemplo (16), no qual ocorre uma mudança da configuração de mão do sinal EU.

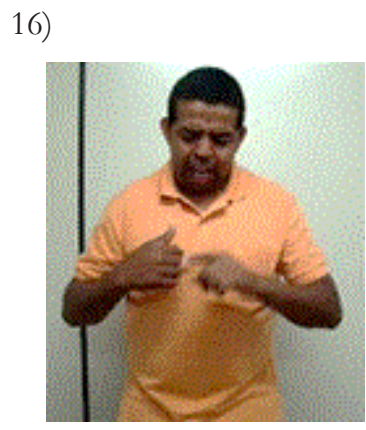

EU

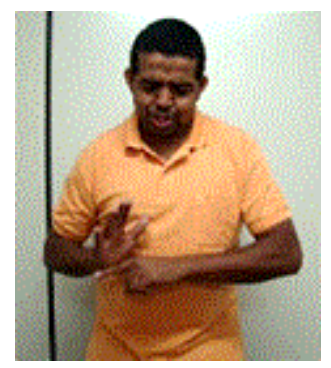

AJUDAR

Eu ajudo. (PS: 03:32 - 03:33) (foto da autora)

Quando seguido do sinal AJUDAR - que em sua forma isolada apresenta a CM (ver exemplo 17), o sinal EU, no enunciado "Eu ajudo", apresenta a configuração de mão CM Ẽ , resultante da assimilação parcial da CM

$\mathrm{O}$ sinal EU, quando falado isoladamente, apresenta a configuração de mão CM como se pode ver no exemplo (17). 
17)

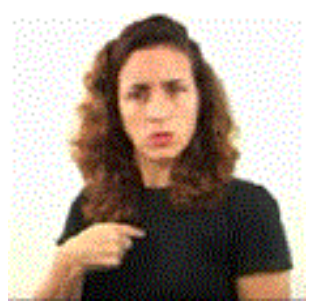

EU - forma isolada (Fonte: Acesso Brasil)
18)

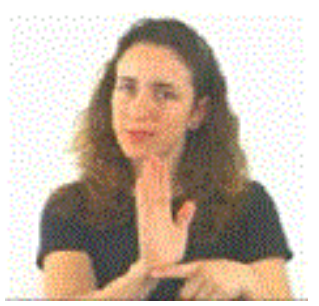

AJUDAR - forma isolada (Fonte: Acesso Brasil)

Note-se que, nesse caso, trata-se de uma assimilação forte e regressiva, na qual o elemento alvo EU altera sua CM subjacente e antecede o sinal AJUDAR, que provoca a assimilação.

Como vimos anteriormente, McCleary e Leite (2012, p. 20) registraram uma assimilação semelhante, a da CM de QUERER na realização de EU, na sequência EU QUERER.

\section{Assimilação de Ponto de articulação (PA)}

Processos de assimilação também podem alterar a mudança do ponto de articulação (ou a localização) da realização do sinal.

$\mathrm{Na}$ Libras esse tipo de assimilação é encontrado, por exemplo, em (19), 'Os médicos usam máscaras'. Nesse caso, a assimilação é regressiva, pois o sinal MÉDICO, que sofre a assimilação - realizado diante da boca do sinalizador, em posição mais alta do que o usual-precedeo sinal MÁSCARA.

19)

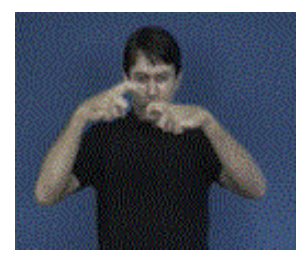

MÉDICO

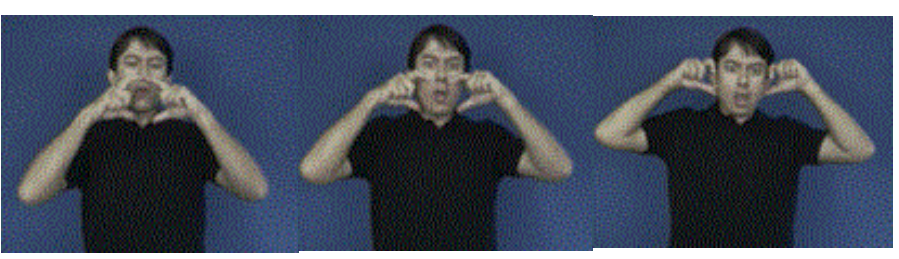

MÁSCARA

Os médicos usam máscaras. (KD: 01:48 - 02:02) (foto da autora) 
Como podemos ver no exemplo (20), a forma isolada de MÉDICO é realizada no espaço neutro, na altura do peito do sinalizador, enquanto a forma isolada de MÁSCARA (21) é realizada diante da boca.

20)

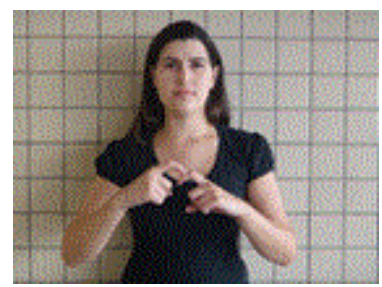

MÉDICO - forma isolada (foto da autora)
21)

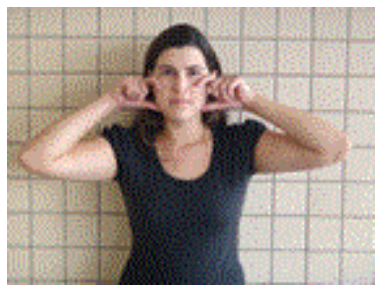

MÁSCARA - forma isolada (foto da autora)

\section{Assimilação de Movimento (M)}

A assimilação de movimento pode acontecer pela interferência de um sinal em que ocorra algum tipo de movimento. No exemplo (22) 'A enfermeira levou o bebê', ocorre a assimilação do movimento de oscilação repetida esquerda-direita do sinal BEBE no sinal $\mathrm{CL}_{\text {pessoal }}-\mathrm{ANDAR}$, no qual o movimento, na sua forma isolada, é linear e para a frente, como se pode ver no exemplo (23).

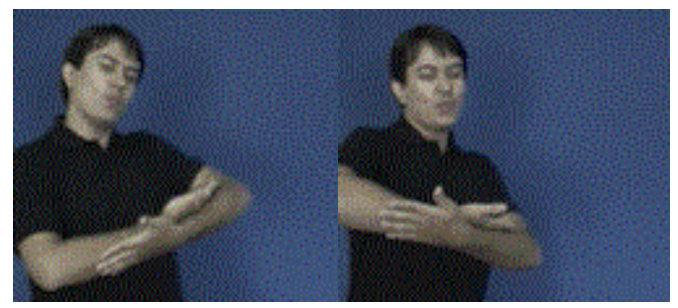

BEBÊ 

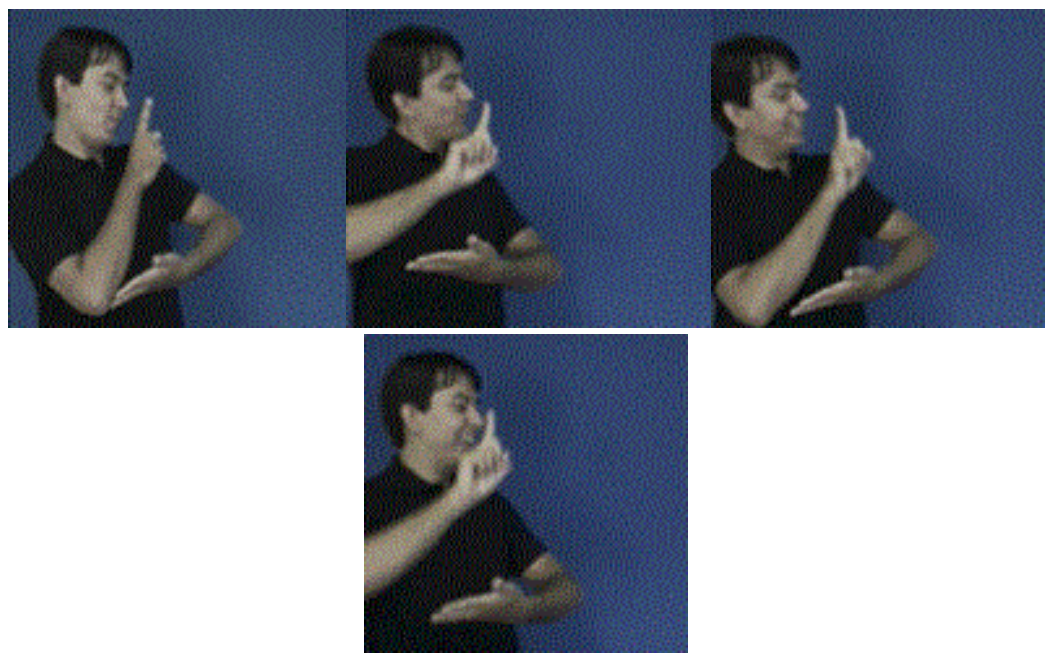

$\mathrm{CL}_{\text {pessoa1 }}-\mathrm{ANDAR}$

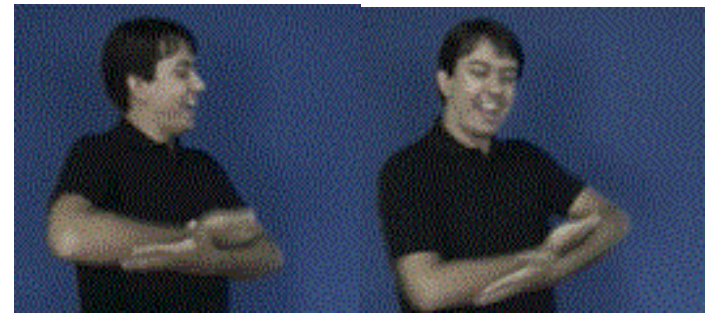

BEBÊ

A enfermeira levou o bebê. (KD: 02:17 - 02:22) (foto da autora)

23)

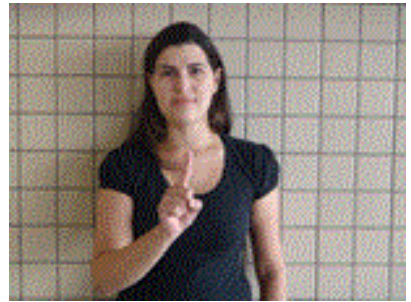

$\mathrm{CL}_{\text {pessoa1 }}$-ANDAR- forma isolada (foto da autora) 
Esse processo, que envolve movimento, merece um estudo mais aprofundado visto que há diferentes alternativas a considerar. Uma interpretação, do ponto de vista fonológico, seria incluir esse tipo de ocorrência entre as assimilações simultâneas, considerando que o elemento que provoca a assimilação, BEBÊ, ocorre ao mesmo tempo que o sinal alvo. Outra possibilidade seria considerar a realização do $\mathrm{CL}_{\text {pessoal }}$ -ANDAR com o movimento de oscilação repetida esquerda-direita do sinal BEBÊ, como a realização de duas glosas simultâneas $\mathrm{BEBE}^{\wedge} \mathrm{CL}_{\text {pessoal }}$ -ANDAR, num constituinte morfológico só.

\section{Assimilação de orientação da mão (Or)}

A assimilação de orientação da mão é uma alteração da posição da palma da mão por influência da orientação de outro sinal.

No exemplo 'Na árvore, o homem subiu, desceu e viu...' (24), ocorre uma assimilação de orientação do sinal DESCER, que na sua forma isolada é realizado com um $\mathrm{CL}_{\text {pessoa3 }}$ orientado para o corpo do sinalizador e para baixo. Devido à interferência da orientação do sinal ÁRVORE, que apresenta a CM para cima, o sinal DESCER altera sua orientação para cima, num processo de assimilação progressiva.

24)

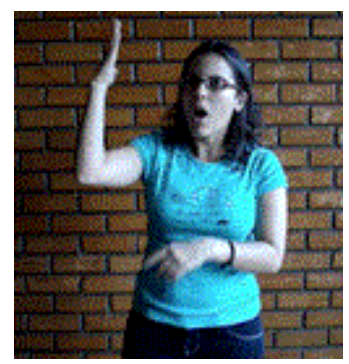

ÁRVORE

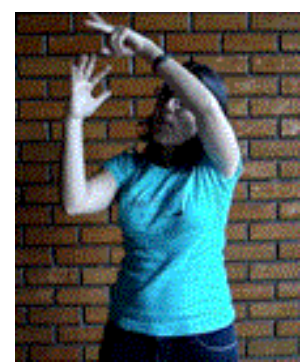

ÁRVORE-HOMEM-SUBIR 

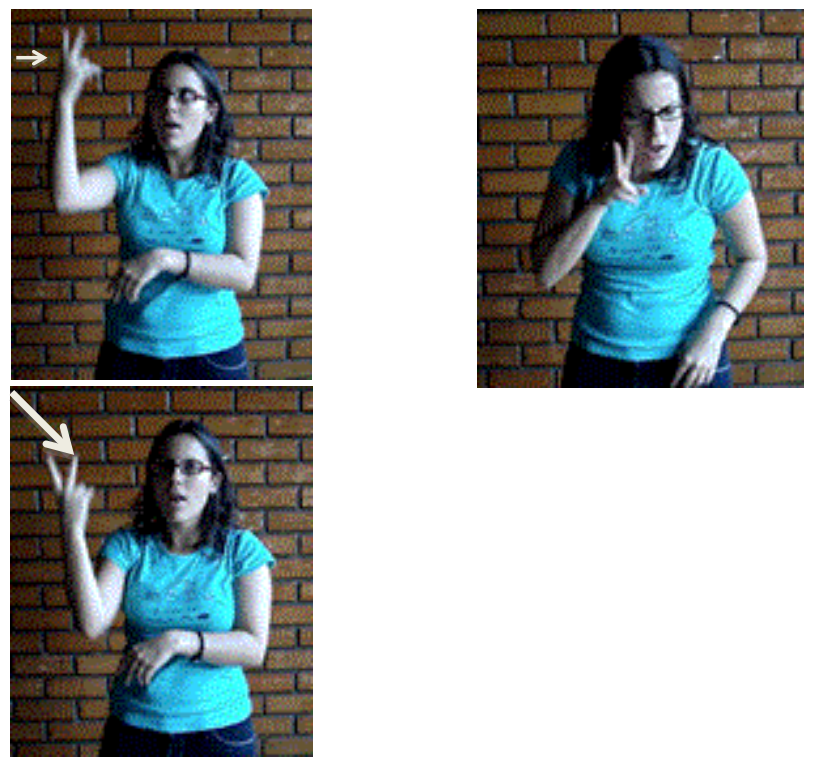

HOMEM-DESCER

VER

$\mathrm{Na}$ árvore, o homem subiu, desceu e viu...(P: 02:34 - 02:37)

(foto da autora)

Por outro lado, esse exemplo apresenta mais um tipo de assimilação: o $\mathrm{CL}_{\text {pessoa3 }}$ que integra o sinal DESCER, em sua forma isolada é realizado com a CM É como se pode ver no exemplo (25) mas, no enunciado acima, esse classificador ocorre com a CM em um processo de assimilação regressiva, provocado pela CM de VER. Pode-se supor que essa assimilação seja também devida à influência da CM de ÁRVORE, de modo que, com respeito à mudança da CM हैं para a CM , haveria um processo ensanduichado, no qual o sinal DESCER sofreria uma assimilação parcial da CM de ÁRVORE e uma assimilação total da CM de VER 


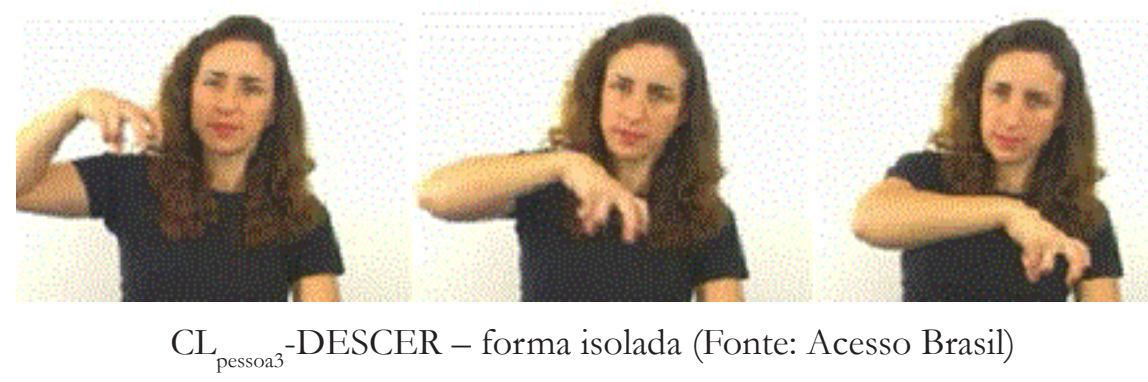

\section{Considerações finais}

Neste estudo, baseado em dados produzidos por surdos falantes de Libras, é possível verificar, como era esperado, que o fenômeno da assimilação é muito comum nessa língua. Há diferentes tipos de assimilação, que correspondem em grande parte aos tipos encontrados em línguas orais e em outras línguas de sinais, tais como: as assimilações regressiva ou progressiva. São numerosos os exemplos de assimilação total bem como de assimilação parcial.

Alguns tipos de assimilação que identificamos nesses dados e que não haviam sido documentados anteriormente são (1) a assimilação que denominamos simultânea e (2) a distinção entre assimilação forte e fraca. Neste ponto, essas duas assimilações são fenômenos próprios das línguas de sinais, visto que, no caso da assimilação simultânea, dependese da realização simultânea de dois segmentos (duas CMs, na Libras) e, no caso da assimilação fraca, essa só pode ocorrer porque um dos articuladores pode não ser necessário na realização de um sinal, ficando 'à toa' e podendo, por isso, manter ou antecipar uma configuração de mão de outro sinal, sem afetar a essência do sinal em questão. Por essas razões, são processos que não ocorrem em línguas orais, sendo, portanto, exclusivos de línguas de sinais. 
Embora houvesse uma referência superficial a diferente tipo de assimilação na $\mathrm{ASL}^{6}$, são apresentados, na Libras, processos de assimilação de todos os tipos de parâmetros: ao lado da assimilação da CM, encontramos processos de assimilação de ponto de articulação, de movimento e de orientação de mão.

O presente trabalho nos diz que a perseveração ou a antecipação da mão passiva em um sinal que utiliza apenas uma mão, constitui um tipo especial de assimilação, a assimilação fraca, pois não afeta a forma básica do sinal. Esse tipo de processo, que também é muito frequente na Libras, é melhor caracterizado como uma assimilação fraca, na qual a mão passiva de um sinal vizinho é mantida ou antecipada na realização do sinal com assimilação.

Os processos de assimilação em geral, tanto das línguas de sinais como das línguas orais podem ser explicados por um princípio de economia dos movimentos, seja dos movimentos manuais e nãomanuais das línguas de sinais, seja dos movimentos do aparelho fonador nas línguas orais - a assimilação nada mais é do que uma facilitação da realização dos segmentos que se sucedem ou se sobrepõem na composição dos enunciados.

\section{Referências}

DINIZ, Heloise Gripp. (2011). A história da Língua de Sinais dos surdos brasileiros: Um estudo descritivo de mudanças fonológicas e lexicais. Petrópolis, RJ: Arara Azul.

${ }^{6}$ Liddell e Johnson (1989), mencionam que detém do exemplo de assimilação de CM que apresentam, ocorrem nessa língua processos de assimilação de outros parâmetros que ainda requerem ser analisadas. Além dessa referência, Sandler e Lillo-Martin (2006, p. 156) relatam um caso excepcional de orientação de mão associada à CM. 
Dicionário de Libras (Acesso Brasil). Disponível em: http://www. acessobrasil.org.br/libras/. Acesso em: 10 de maio de 2012.

FERREIRA-BRITO, Lucinda. (1995). Por Uma Gramática de Língua de Sinais. Rio de Janeiro: Tempo Brasileira: UFRJ.

GABAS JÚNIOR, N. (2008). Linguística Histórica. In: MUSSALIM, F. e BENTES, A. C., Introdução à linguística: domínios e fronteiras, v. 1, p. 83. São Paulo: Cortez.

História de The pear story. Disponível em: https://www.youtube.com/ watch?v=bRNSTxTpG7U. Acesso em: 10 de maio de 2012.

LEITE, Tarcísio de A. (2008). A segmentação da língua de sinais brasileira (Libras): Um estudo linguístico descritivo a partir da conversação espontânea entre surdos. Tese de doutorado. São Paulo: USP.

LIDDELL, Scott K. Robert E. Johnson. (1989). American Sign Language: The Phonological Base. Volume 64 - Fall.

MCCLEARY, Leland. Leite, Tarcísio. (2012). Turn-taking in Brazilian Sign Language: Evidence from overlap.To be published in Journal of Interactional Research in Communication Disorders.

PIMENTA, Nelson. Ronice Muller de Quadros. (2006). Curso de língua de sinais brasileira, v.1, Iniciante. Rio de Janeiro: LSB Vídeo.

SANDLER, Wendy; LILLO-MARTIN, Diane. (2006). Sign Language and Linguistic Universals. Cambridge.

STOKOE, William. (1960). Sign Language Structure: An Outline of the Visual Communication Systems of the American Deafs. Studies in Linguistics, Occasional Papers 8. Silver Sping MD: Linstock Press. 
VALLI, Clayton, Ceil Lucas, Kristin J. Mulrooney, Miako Villanueva. (2011). Linguistics of American Sign Language: an introduction. $5^{\text {th }}$ edition. 